\title{
Subcutaneous Zygomycosis Due to Basidiobolus ranarum: A Case Report from Maharastra, India
}

\author{
Mani Anand, ${ }^{1}$ Sanjay D. Deshmukh, ${ }^{1}$ Dilip P. Pande, ${ }^{2}$ Suresh Naik, ${ }^{2}$ \\ and Dhyaneshwari P. Ghadage ${ }^{3}$ \\ ${ }^{1}$ Department of Pathology, Smt. Kashibai Navale Medical College and General Hospital, Narhe, Off Pune-Mumbai Bypass, \\ Pune 411041, Maharashtra, India \\ ${ }^{2}$ Department of Surgery, Smt. Kashibai Navale Medical College and General Hospital, Narhe, Pune 411041, Maharashtra, India \\ ${ }^{3}$ Department of Microbiology, Smt. Kashibai Navale Medical College and General Hospital, Narhe, Pune 411041, Maharashtra, India \\ Correspondence should be addressed to Mani Anand, manianand291@yahoo.com
}

Received 15 September 2010; Revised 3 November 2010; Accepted 22 November 2010

Academic Editor: Luis Eduardo Cuevas

Copyright ( $) 2010$ Mani Anand et al. This is an open access article distributed under the Creative Commons Attribution License, which permits unrestricted use, distribution, and reproduction in any medium, provided the original work is properly cited.

\begin{abstract}
Entomophthoromycosis is a rare entity. We hereby report a case of entomophthoromycosis in a three-year-old Asian child who presented with a painless, nontender, rapidly increasing large swelling on the thigh of six months duration, which was initially misdiagnosed as a soft tissue tumor and resected. The cause of misleading diagnosis was rapid growth of the lesion in a short duration of time, indicating the possibility of a tumor. Histopathological examination revealed an inflammatory lesion with aseptate fungal hyphae and the characteristic Splendore-Hoeppli phenomenon. Microbiological examination identified the fungus as Basidiobolus ranarum. Complete excision of the lesion followed by antifungal therapy was associated with complete recovery. Entomophthoromycosis should be considered early when children from endemic areas present with unusual, rapid-growing lesions of the subcutaneous region. In order to emphasize tumor-like presentation of zygomycosis, we are presenting this case.
\end{abstract}

\section{Introduction}

Entomophthoromycosis (subcutaneous zygomycosis) is a sporadic subcutaneous infection that is largely restricted to tropical areas of Africa, Asia, and South America. It presents in two clinically distinct forms. Subcutaneous zygomycosis, caused by Basidiobolus ranarum and rhinofacial zygomycosis caused by Conidiobolus coronatus. Neither of these two forms occur preferentially in patients with underlying disease or defective immunity [1]. Entomophthoromycosis is characterized by the formation of firm and nontender swellings, generally on the extremities, trunk, and rarely other parts of the body [2]. Subcutaneous zygomycosis can also mimic soft tissue tumors [3]. We present a case of a 3year-old Asian boy with a large, rapid-growing zygomycotic lesion of the left thigh which was initially misdiagnosed as a soft tissue tumor, emphasizing the importance of rapid and thorough diagnosis with a high index of suspicion, especially in endemic areas.

\section{Case Presentation}

A three-year-old male child was admitted with the complains of a gradually increasing painless swelling over the left thigh of 6 months duration. There was a history of trauma to the site three months prior to the onset of the present swelling.

Local examination showed a $14 \times 8 \mathrm{~cm}$ nontender indurated subcutaneous swelling on the left thigh over the anterolateral, medial, and posterior aspect. The swelling was firm in consistency with smooth and rounded edges and was freely mobile over the underlying structures. The overlying skin was lobulated and hyperpigmented and showed a $2 \mathrm{~cm}$ linear scar. There was no regional lymphadenopathy. Based on the history and clinical presentation, a diagnosis of soft tissue tumor was considered.

The Rest of the general and systemic examination was normal. Routine laboratory investigations revealed an elevated total leukocyte count $(27,400 / \mathrm{cmm})$. His HIV status was negative. X-ray of the thigh revealed a soft tissue swelling 


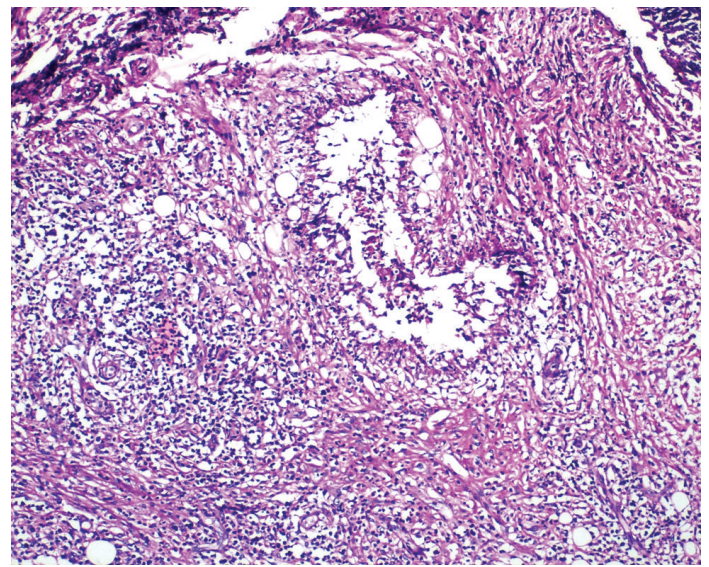

Figure 1: Low power view of the lesion showing granulomatous reaction, mixed inflammatory infiltration, and fibrosis $(\mathrm{H} \& \mathrm{E}$, 100x).

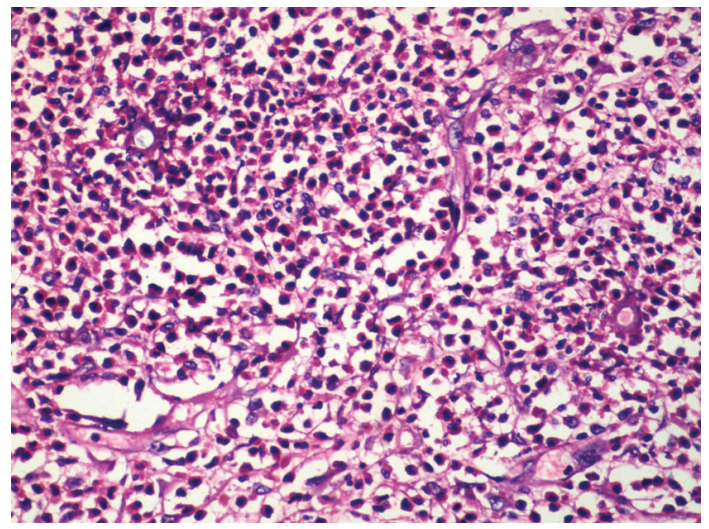

FIGURE 2: Splendore-Hoeppli bodies surrounded by eosinophils, polymorphs and few histiocytes. (H\&E, 400x).

without any bone involvement. Fine needle aspiration cytology of the swelling was suggestive of a spindle cell lesion with few inflammatory cells. The swelling was completely excised and sent for histopathological examination.

The excised specimen had a grey-white nodular cut surface. The haematoxylin- and eosin- stained sections revealed normal skin with subcutaneous tissue showing inflammatory granulomatous reaction with diffuse and dense infiltration by eosinophils, polymorphs, histiocytes, plasma cells, lymphocytes, and few multinucleated giant cells. The central portion showed fragments of aseptate hyphae surrounded by a peculiar eosinophilic mass and the Splendore-Hoeppli phenomenon (Figures 1 and 2). Periodic acid Schiff (Figure 3) and Gomori methenamine silver (Figure 4) stain for fungus showed few, broad, thinwalled, and aseptate fungal hyphae.

Culture on Sabouraud's dextrose agar after three days of incubation showed furrowed creamy-brown radially folded colonies. Lactophenol cotton blue wet mount demonstrated aseptate hyphae and smooth-walled zygospores with characteristic conjugation beaks, which confirmed the fungus to be Basidiobolus ranarum.

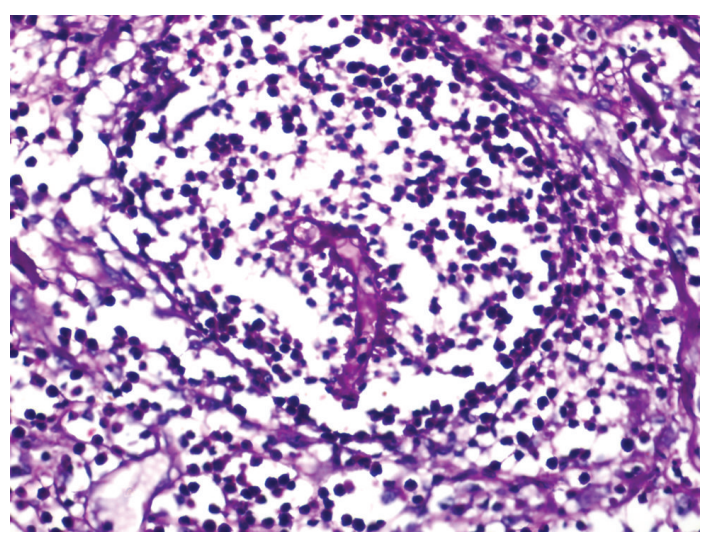

FIgure 3: Photomicrograph showing aseptate fungal hyphal filament on Periodic acid Schiff (PAS, 400x),

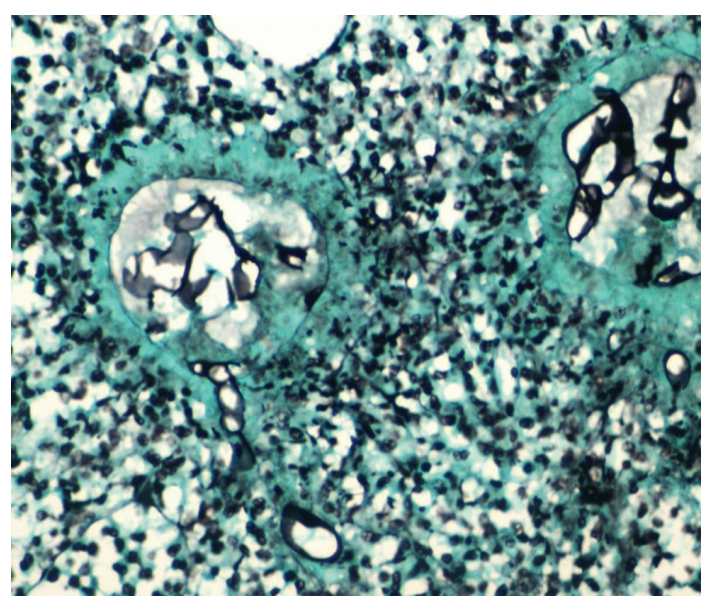

FIgURE 4: Photomicrograph showing Splendore-Hoeppli bodies on Gomori silver methenamine silver (GMS) stain. GMS delineates aseptate hyphal filaments (GMS, 400x).

After complete excision and in view of the histopathological report, the patient was started on oral potassium iodide $40 \mathrm{mg} / \mathrm{kg}$ per day. After one week of treatment with potassium iodide, oral itraconazole was added in a dose of $100 \mathrm{mg} /$ day and the entire treatment continued for six months. The recovery was uneventful and the patient was discharged on the 10th postoperative day. After six months of followup there was no recurrence. The hematological examination showed total and differential counts within normal limits indicating complete recovery.

\section{Discussion}

In 1956 in Indonesia, Lei-Kian Joe described the first case of entomophthoromycosis in humans; the infectious agent was Basidiobolus ranarum. In 1965 Bras reported a case in a Jamaican native caused by Conidiobolus coronatus. Worldwide, there have been about 250 reported cases caused by Basidiobolus haptosporus. All of them affecting trunk and extremities, and usually seen in children. Approximately 160 cases caused by Conidiobolus coronatus have been reported 
[4]. Entomophthoromycosis (subcutaneous zygomycosis) caused by Basidiobolus ranarum manifests clinically as a firm, painless, disciform nodule on the trunk or extremities, which if untreated may enlarge and spread locally, but systemic dissemination is extremely uncommon. Rhinofacial zygomycosis caused by Conidiobolus coronatus is a locally progressive infection of the nasal cavity, paranasal sinuses, and soft tissues of the face. The microscopic features of both forms of entomophthoromycosis are similar and give rise to an eosinophilic granuloma situated in the subcutaneous tissues [5].

The disease usually occurs in children, less often in adolescents, and rarely in adults. Males are much more frequently affected than females [6].

Chiewchanvit et al., studied eight cases of entomophthoromycosis out of which five patients were diagnosed as subcutaneous zygomycosis (females aged 7-77 years), two rhinofacial zygomycosis (26 and 39 years, males) and one case was of gastrointestinal entomophthoromycosis (34 year, male) [7].

In a study of ten cases of entomophthoromycosis by Krishnan et al., eight were caused by Basidiobolus haptosporus, predominantly in children below ten years of age, and thigh was the most commonly involved site, as in our case [8].

Entomophthoromycosis has been known as a saprophytic fungus present in soil, decaying fruit, and vegetable matter as well as in the gut of amphibians and reptiles [9].

The mode of infection is not known but it is assumed that traumatic implantation may play a role [10]. The presence of an irregular scar over the swelling in our patient indicated that the infection was probably initiated by penetrating trauma. The infection can be transmitted by insect bites or by transepidermal inoculation with contaminated vegetable matter.

Entomophthoromycosis is a potentially curable disease which can masquerade as a neoplasm. Cases have been reported in The literature, where subcutaneous zygomycosis presented as a mimicker of soft tissue tumor, synovial sarcoma, and Burkitt's lymphoma [10-12]. In our patient also, such a large size of the swelling, its duration and clinical presentation misguided the clinician to diagnose it as a soft tissue tumor.

Histologically, basidiobolomycosis is associated with eosinophilic infiltration which was also the case in our patient. This has been postulated to be due to a mixture of Th1 (granuloma) and Th2 type of immune response. This causes the release of cytokines like IL- 4 and IL-10 which in turn are helpful in recruiting eosinophils to the affected site [5]. The other histological features are presence of broad thin walled infrequently septate hyphal fragments enveloped by eosinophilic "Splendore-Hoeppli" material [1].

In the past, clinical isolates of Basidiobolus were classified as B. ranarum, B. meristosporus, and B. haptosporus. But recent taxonomic studies based on antigenic analysis, isoenzyme banding, and restriction enzyme analysis of rDNA indicate that all human pathogens belong to B. ranarum [9].
Most patients with entomophthoromycosis respond very well to oral potassium iodide therapy as well to azoles, particularly itraconazole [9].

To summarise, subcutaneous zygomycosis presents as a painless subcutaneous swelling usually in young age. It is usually seen in the natives of Asia, Africa, and South America. Demonstration of the aseptate fungal hyphae on histopathology and confirmation by culture clinches the diagnosis. Treatment with potassium iodide and azoles is the gold standard.

Our experience with this case highlights the importance of awareness and early recognition of this condition to prevent disfigurement produced by advanced disease, misdiagnosis, and unnecessary surgical intervention.

\section{References}

[1] F. W. Chandler and J. C. Watts, "Fungal Diseases," in Anderson's Pathology, I. Damjanov and J. Linder, Eds., Mosby, St. Louis, Mo, USA, 10th edition, 1996.

[2] M. R. Naniwadekar, S. V. Jagtap, B. P. Nikam, and K. D. Sanghavi, "Subcutaneous phycomycosis in a child," Online Journal of Health and Allied Sciences, vol. 8, no. 3, p. 14, 2009.

[3] S. P. Thotan, V. Kumar, A. Gupta, A. Mallya, and S. Rao, "Subcutaneous phycomycosis-fungal infection mimicking a soft tissue tumor: a case report and review of literature," Journal of Tropical Pediatrics, vol. 56, no. 1, pp. 65-66, 2010.

[4] E. Drouhet and P. Ravisse, "Entomophthoromycosis", in Current Topics in Medical Mycology, M. Borgers, R. Hay, and M. G. Rinaldi, Eds., vol. 5, Prous Science, Barcelona, Spain, 1994.

[5] S. Rane, A. Jayaraman, S. Puranik, S. Deshmukh, and V. Bapat, "Entomopthoromycosis-Report of four cases," Indian Journal of Dermatology, Venereology and Leprology, vol. 68, no. 5, pp. 296-297, 2002.

[6] H. C. Gugnani, "A review of zygomycosis due to Basidiobolus ranarum," European Journal of Epidemiology, vol. 15, no. 10, pp. 923-929, 1999.

[7] S. Chiewchanvit, C. Pruksachatkunakorn, N. Vanittanakom et al., "Entomophthoromycosis in Maharaj Nakorn Chiang Mai Hospital," Journal of the Medical Association of Thailand, vol. 85, no. 10, pp. 1089-1094, 2002.

[8] S. G. S. Krishnan, G. Sentamilselvi, A. Kamalam, K. A. Das, and C. Janaki, "Entomophthoromycosis in India - A 4-year study," Mycoses, vol. 41, no. 1-2, pp. 55-58, 1998.

[9] S. Sujatha, C. Sheeladevi, A. B. Khyriem, S. C. Parija, and D. M. Thappa, "Subcutaneous zygomycosis caused by Basidiobolus ranarum-a case report," Indian Journal of Medical Microbiology, vol. 21, no. 3, pp. 205-206, 2003.

[10] Z. U. Khan, M. Khoursheed, R. Makar et al., "Basidiobolus ranarum as an etiological agent of gastrointestinal zygomycosis," Journal of Clinical Microbiology, vol. 39, no. 6, pp. 2360$2363,2001$.

[11] Sivaraman, D. M. Thappa, Karthikeyan, and Hemanthkumar, "Subcutaneous phycomycosis mimicking synovial sarcoma," International Journal of Dermatology, vol. 38, no. 12, pp. 920923, 1999.

[12] A. L. Bittencourt, G. Serra, and M. Sadigursky, "Subcutaneous zygomycosis caused by Basidiobolus haptosporus: presentation of a case mimicking Burkitt's lymphoma," American Journal of Tropical Medicine and Hygiene, vol. 31, no. 2, pp. 370-373, 1982. 


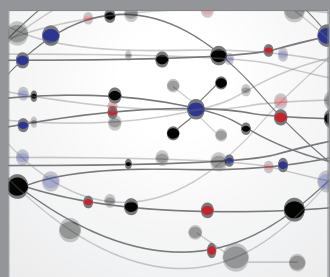

The Scientific World Journal
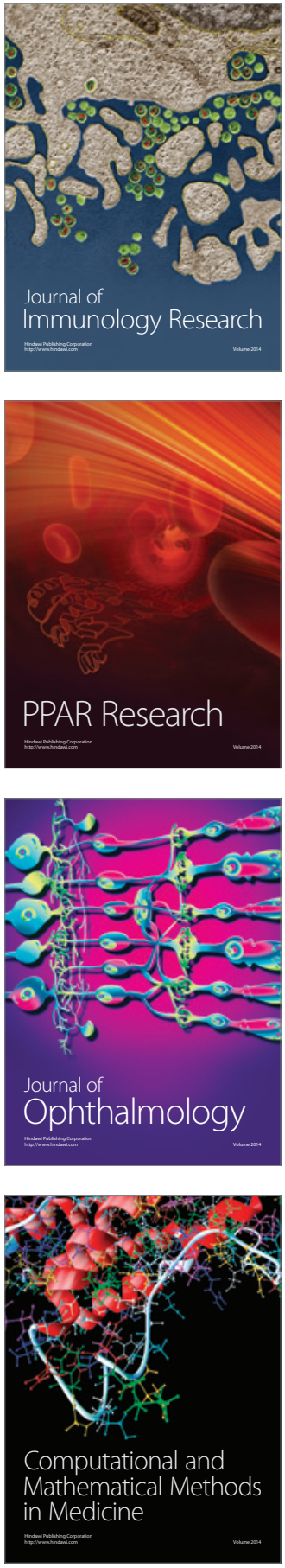

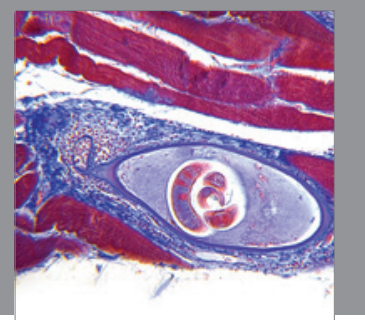

Gastroenterology

Research and Practice
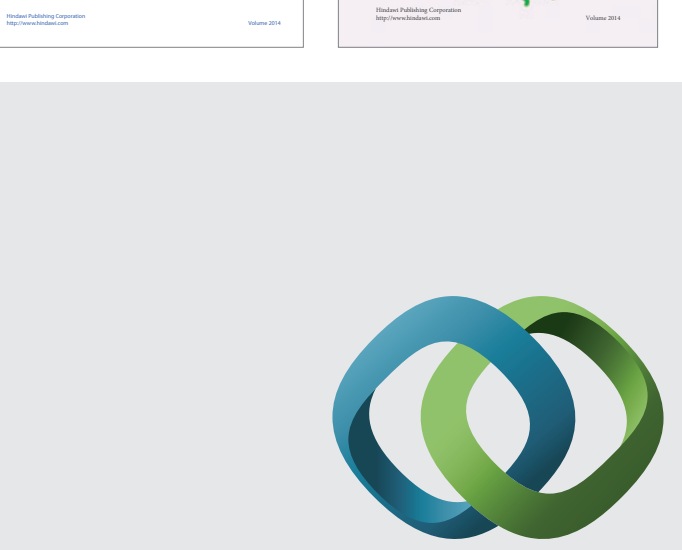

\section{Hindawi}

Submit your manuscripts at

http://www.hindawi.com
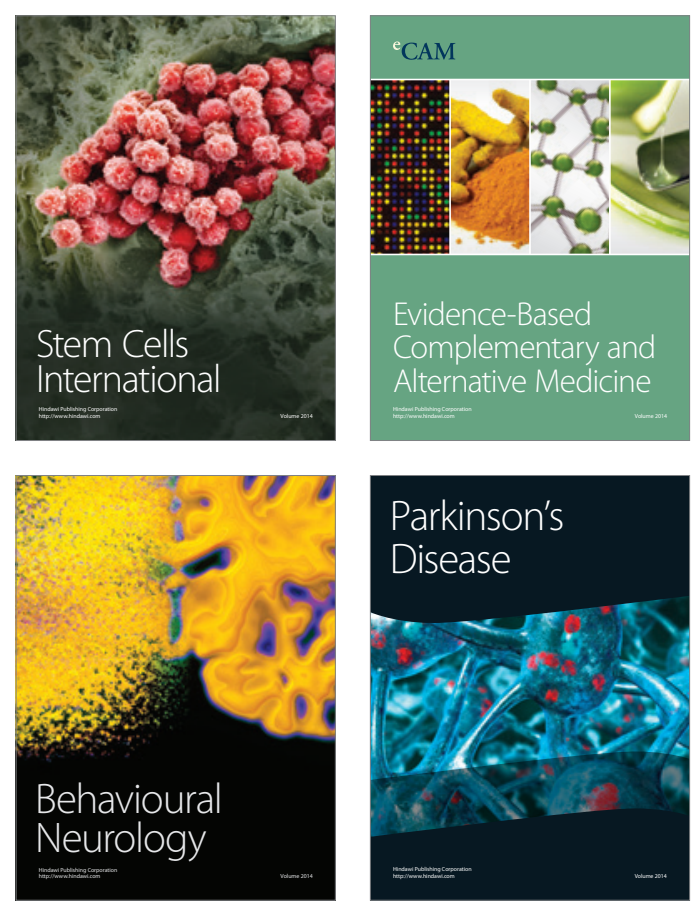

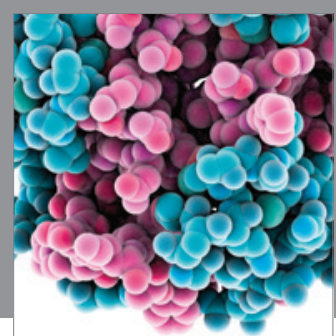

Journal of
Diabetes Research

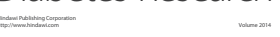

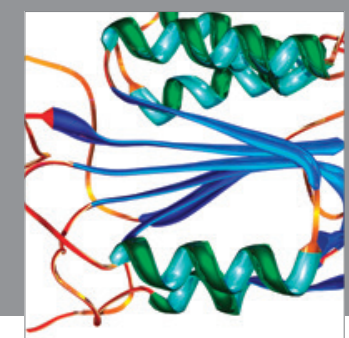

Disease Markers
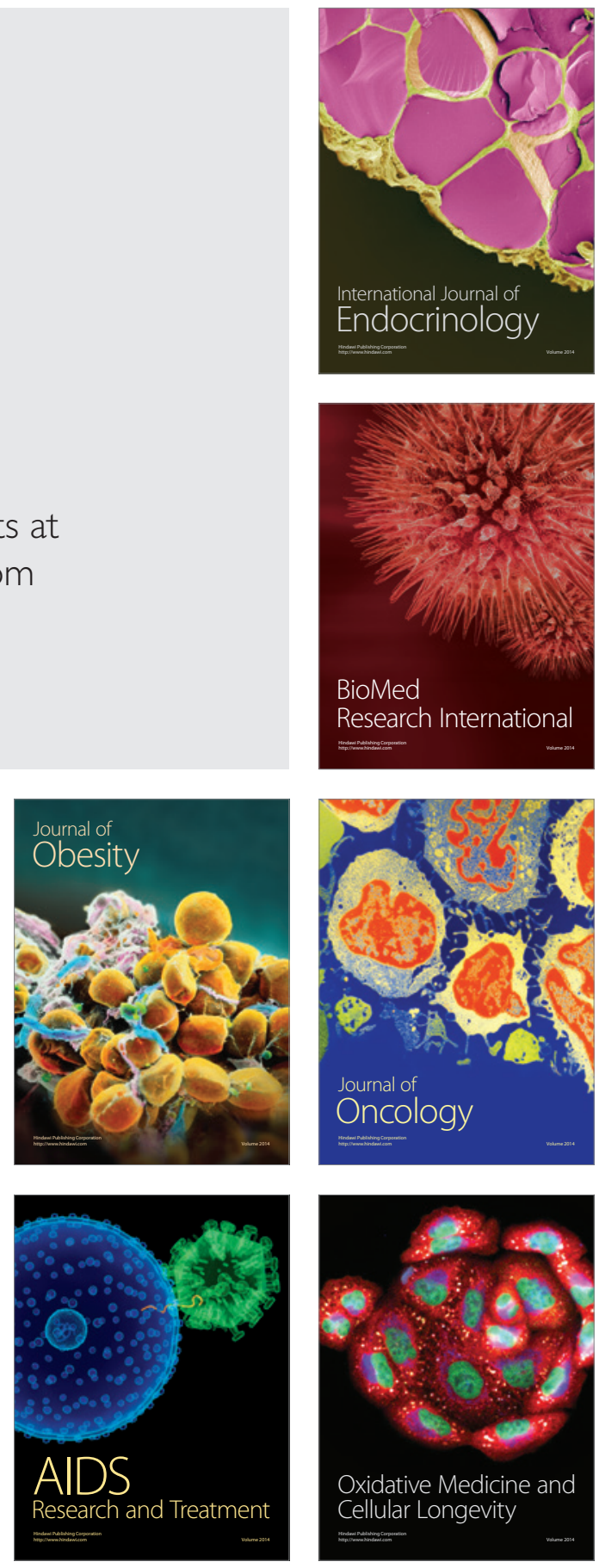